\title{
Factors Associated with the Occurrence of Metastatic Dissemination in Rectal Cancer
}

ISSN: 2637-7632

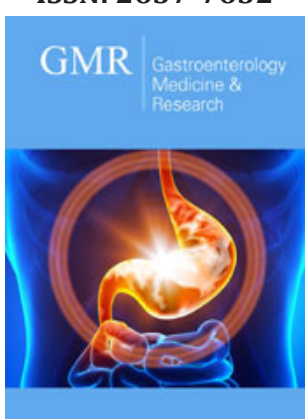

*Corresponding author: Ana Lazarova, Department of Radiology, St.Kiril and Methodius, Medical faculty, University Clinic for surgery disease St.Naum Ohridski,Macedonia

Submission: 温 December 21, 2020

Published: 漈January 25, 2021

Volume 5 - Issue 3

How to cite this article: Ana Lazarova. Factors Associated with the Occurrence of Metastatic Dissemination in Rectal Cancer. Gastro Med Res. 5(3). GMR. 000614. 2021 DOI: $10.31031 /$ GMR.2021.05.000614

Copyright@ Ana Lazarova, This article is distributed under the terms of the Creative Commons Attribution 4.0 International License, which permits unrestricted use and redistribution provided that the original author and source are credited.

\section{Ana Lazarova*}

Department of Radiology, Medical faculty, University Clinic for surgery disease St. NaumOhridski, Macedonia

\section{Abstract}

Introduction: The occurrence of metastases in rectal cancer disease is an additional important worrying factor not only in the patient but also in the surgeon due to their often fatal outcome. Up to $20 \%$ of patients with rectal cancer have metastatic disease at the stage of detection of the primary disease. Despite the development of preoperative neoadjuvant treatment, preoperative chemo-radiotherapy in rectal cancer, metastases pose a challenge in the proper management of the disease, especially as they significantly reduce the 5 -year survival rate.

Aim of the study: The aim of this study is to highlight the significant factors that have influence in the occurrence of metastatic disseminated disease in the patients with primary diagnosed rectal cancer.

Material and Methods: This is a prospective study which include a 82 patients aged from 43 to 87 years, with an average age of 66 years with previously colonoscopy proven rectal cancer. Before the operation magnetic resonance images (MRI) was made at-1.5T magnet for determination the MRI T and $\mathrm{N}$ staging preoperatively. For detection of distant metastatic deposits, $\mathrm{M}$ staging, computer tomography (CT) after dynamic application of intra venous contrast medium on lungs and whole abdomen was done in all 82 patients.

Results: Metastatic deposits were found in 14 (17.07\%) of 82 patients with rectal cancer disease, of them 12 were male and 2 patients were female. Eleven of the patients had metastatic deposits in the liver, 2 patients had metastatic deposits in the lung and liver at the same time and 1 patient had metastatic deposit in the peritoneum. The occurrence of metastases was significantly associated with pathohistological findings of extra mural vascular invasion EMVI ( $\mathrm{p}=0.014)$. Metastases were detected in 78.6\% (11) EMVIpositive patients and $21.4 \%$ (3) EMVI-negative patients. In the group of patients without metastases, 42.65\% (29) patients were EMVI positive, 57.35\% (39) were EMVI negative. Metastases were detected in one patient with T2 stage of rectal cancer, $18.2 \%$ (10) of T3 stage, most commonly and within T4 stage of rectal cancer-25\% (3) patients. According to the $\mathrm{N}$ stage of rectal cancer metastasis were found in 3 patients N0 stage, 5 patients in N1 and also 5 in N2 and 1 patient in N3 stage of the disease. Depending on the localization of the rectal cancer in 4 patients rectal cancer was localized in the rectosigmoid part, in 4 patients in the proximal part of the rectum, in 2 patients with metastasis, rectal cancer was localized in the mid rectum and in 4 patients rectal cancer was in distal part of the rectum.

Conclusion: Rectal cancer is spread malignant disease worldwide and it is third common malignancy after breast and lung cancer in woman and prostatic and lung cancer in male population. Occurrence of metastatic dissemination when primary rectal cancer has been diagnosed is not so rare condition but is very important to be aware of the factors that are associated with metastatic dissemination of rectal cancer. Knowing the possibility of dissemination can lead to increase the 5 years survival rate and decrease the percentage of incurability.

Keywords: Rectal cancer;Metastatic dissemination;Computer tomography

\section{Introduction}

Despite the development of preoperative neoadjuvant treatment, preoperative chemoradiotherapy in rectal cancer, metastases pose a challenge in the proper management of the disease, especially as they significantly reduce the 5-years survival rate [1,2]. The occurrence of metastases in rectal cancer disease is an additional important worrying factor not only in the patient but also in the surgeon due to their often-fatal outcome. The fact that up to $20 \%$ of patients with rectal cancer have metastatic disease at the stage of detection of the primary disease is challenging and should be taken with great concern $[3,4]$.

The latest research on the spread of metastases focuses on their development at the cellular and molecular level. Unfortunately, the epidemiological knowledge is still insufficient due to the fact that the registers for cancerous diseases do not always include the data for the 
metastatic disease [5]. The "anatomical/mechanical hypothesis" and the "seed and soil" hypothesis are widely accepted to explain the spread of metastases. Recently, the "seed and soil" hypothesis has been specially developed because it examines the tumor-the stromal reaction at the molecular level. Specific tumor cells show a predisposition to certain target organs. Dissemination of initial metastases acts as a seed for further metastatic scattering [2,6]. Blood drains from the proximal rectum and rectosigmoid colon through the portal system to the liver. The next organs from the liver are the lungs through the heart. All parts of the gastrointestinal tract share a common lymphatic drainage-through the cistern to the left subclavian vein-to the lungs. Additionally, metastases may spread through the peritoneal fluid into the peritoneal cavity [7,8]. Mucinous adenocarcinomas show a predisposition to the peritoneum and are more aggressive; mucinous adenocarcinomas are also thought to be genetically predisposed to the peritoneal space $[9,10]$. Due to the embryological origin of the proximal and distal rectum it is clear that they demonstrate a different biology in terms of metastases $[11,12]$. Anatomical localization and histological subtypes have a strong reflection on the manner of metastasis, especially when it comes to an organ other than the liver. Rectal cancer can metastasize to the liver, lungs, central nervous system (CNS), peritoneum, and bones. The prognosis for survival approximately is worst in CNS metastasis- 4 months, bones- 6 months, liver metastases - 9 months, and lung metastases-14 months [13-15].

\section{Material and Methods}

This is a prospective study which includes a 82 patients aged from 43 to 87 years, with an average age of 66 years with previously colonoscopy proven rectal cancer. Before the operation magnetic resonance images (MRI) were made at-1.5T magnet for determination the MRI T and N staging preoperatively. For detection of distant metastatic deposits-M staging, computer tomography (CT) after dynamic application of intra venous contrast medium on lungs and whole abdomen was done in all 82 patients.

\section{Results}

Fourteen (17.07\%) of the patients have metastatic dissemination when primary was diagnosed with rectal cancer disease (Table 1; Figure 1). Ten of male patients have metastatic deposits in the liver, one in liver and lungs and one male patient has metastatic deposits in peritoneum. One female patient has metastatic deposits in the liver and one in both liver and lungs (Figure 2). Patients with and without metastases had a similar mean age on average, about 67 years, and no statistically significant difference $(66.85 \pm 9.1$ vs. $66.62 \pm 10.01$ ) (Table 2) The occurrence of metastases was significantly associated with pathohistological findings of extra mural vascular invasion $(\mathrm{p}=0.014)$. Metastases were detected in 78.6\% (11) EMVI-positive patients and 21.4\% (3) EMVI-negative patients. In the group of patients without metastases, $42.65 \%$ (29) patients were EMVI positive, 57.35\% (39) were EMVI negative (Table 3; Figure 3). Depending on the localization of the rectal cancer in 4 patients rectal cancer was localized in the rectosigmoid part, in 4 patients in the proximal part of the rectum, in 2 patients with metastasis rectal cancer was localized in the mid rectum and in 4 patients rectal cancer was in distal part of the rectum (Table 4; Figure 4). Metastases were detected in one patient with T2 stage of rectal cancer, $18.2 \%$ (10) of T3 stage, most commonly within T4 stage of rectal cancer-25\% (3) patients (Table 5; Figure 5). According to the $\mathrm{N}$ stage of rectal cancer metastasis were found in 3 patients N0 stage, 5 patients in N1 and also 5 in N2 and 1 patient in N3 stage of the disease (Table 6; Figure 6).

Table 1: Distribution of the patients according the presents of Metastatic deposits (MS deposits).

\begin{tabular}{|c|c|}
\hline $\begin{array}{c}\text { Metastatic } \\
\text { Deposits }\end{array}$ & $\mathbf{n}(\%)$ \\
\hline Yes & $14(17.07)$ \\
\hline No & $68(82.93)$ \\
\hline
\end{tabular}

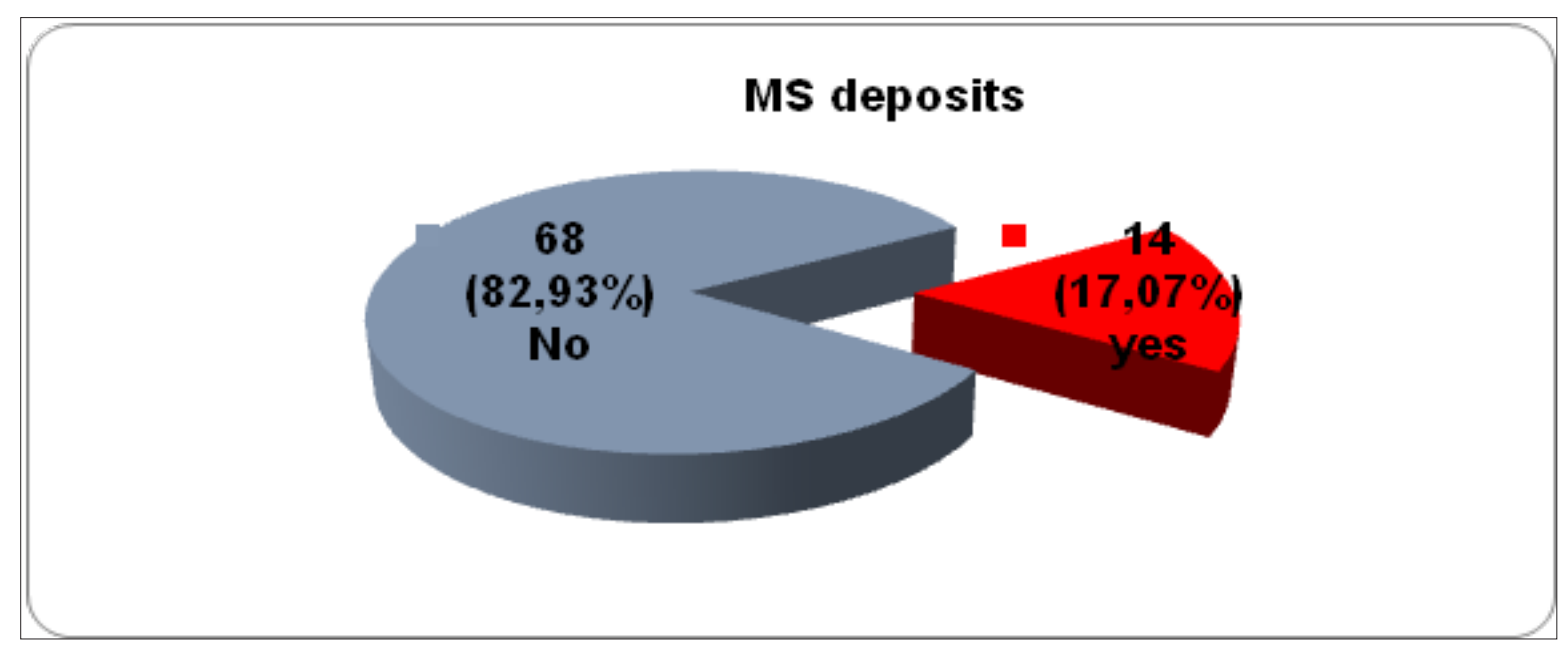

Figure 1: Graphic presentation of metastasis dissemination in patients. 


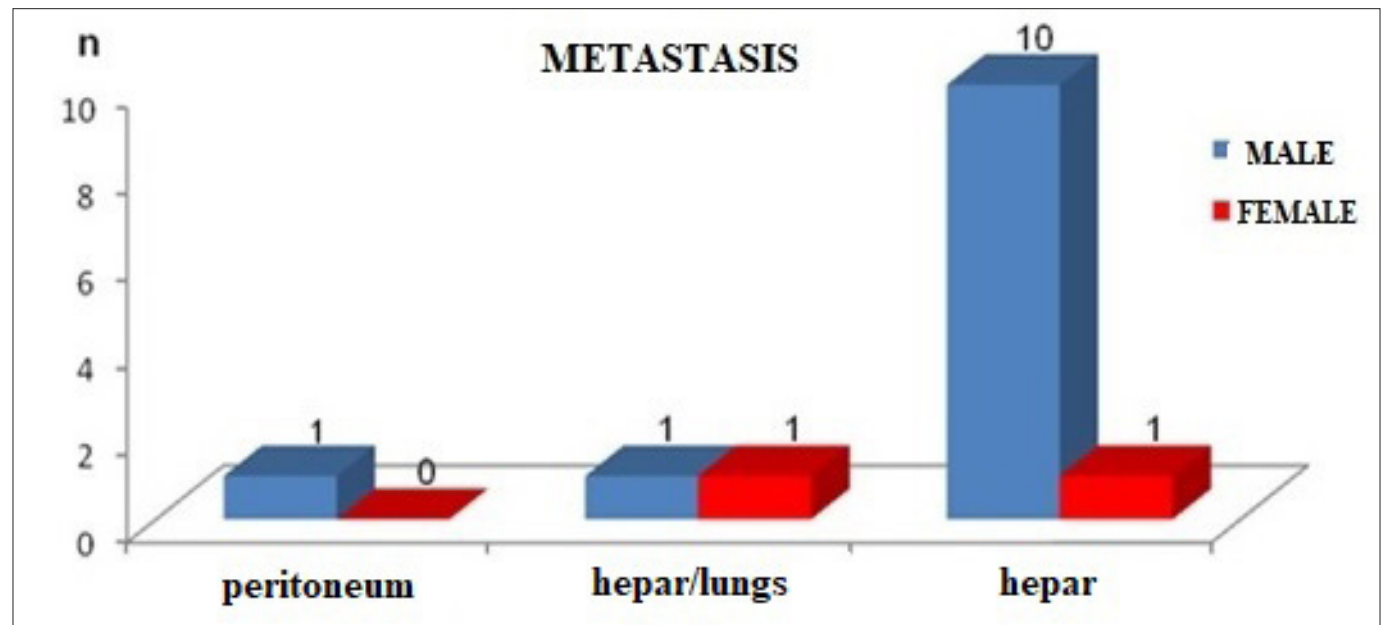

Figure 2: Graphic presentation of localization of metastasis according to patient's gender.

Table 2: Patients age with and without metastatic deposits.

\begin{tabular}{|c|c|c|c|c|}
\hline \multirow{2}{*}{ MS Deposits } & \multicolumn{3}{|c|}{$\begin{array}{c}\text { Descriptive } \\
\text { Statistics (Age) }\end{array}$} \\
\hline & $\mathrm{n}$ & mean \pm SD & Range \\
\hline Yes & 13 & $66.85 \pm 9.1$ & $52-81$ \\
\hline No & 68 & $66.62 \pm 10.01$ & $43-87$ \\
\hline
\end{tabular}

Student $\mathrm{t}=0.076, \mathrm{p}=0.94$.

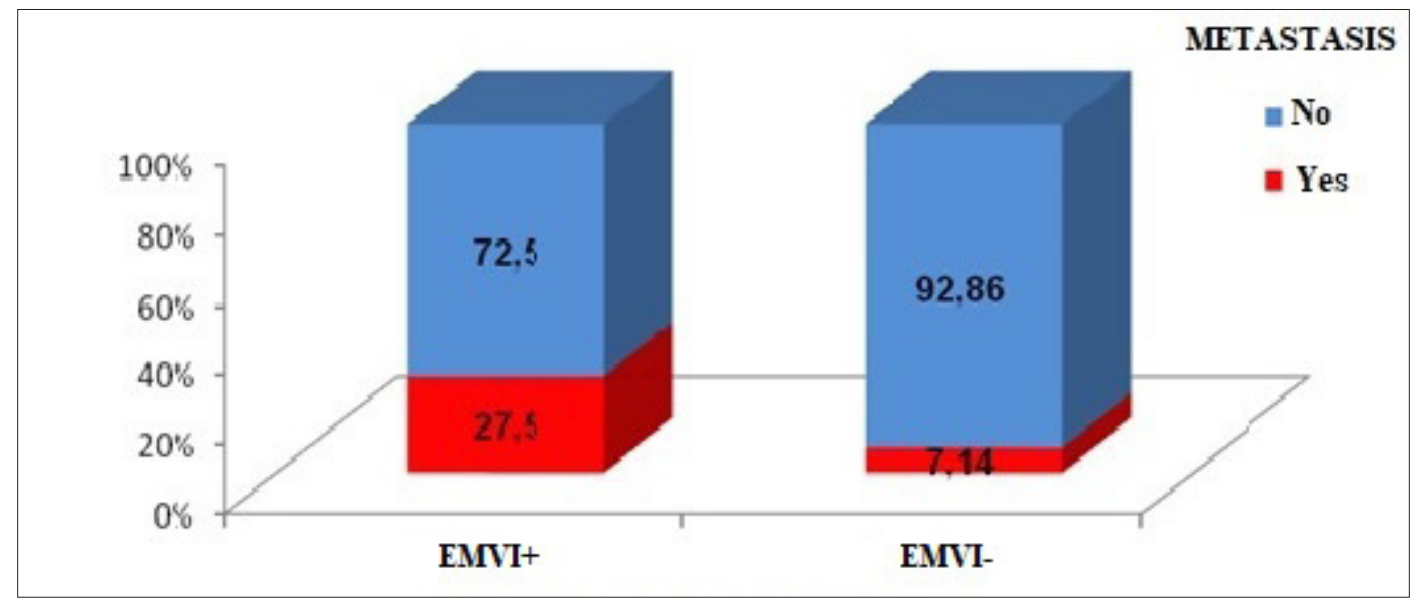

Figure 3: Graphic presentation of metastatic dissemination in EMVI+ and EMVI- status in rectal cancer.

Table 3: Status of extra mural vascular invasion (EMVI) in patients with rectal cancer with and without presents of distant metastasis.

\begin{tabular}{|c|c|c|c|c|}
\hline \multirow{2}{*}{ MS deposits } & \multicolumn{3}{|c|}{ EMVI Patohistology } & \multirow[t]{2}{*}{ p=Level } \\
\hline & $\begin{array}{c}\text { EMVI+ } \\
\text { n (\%) }\end{array}$ & $\begin{array}{l}\text { EMVI- } \\
\text { n (\%) }\end{array}$ & Total & \\
\hline Yes & $11(27.5)$ & $3(7.14)$ & 14 & $\mathrm{p}=0.014 \mathrm{sig}$ \\
\hline No & $29(72.5)$ & $39(92.86)$ & 68 & \\
\hline
\end{tabular}

Chi-square $=5.99, \mathrm{df}=1, \mathrm{p}=0.014$. 


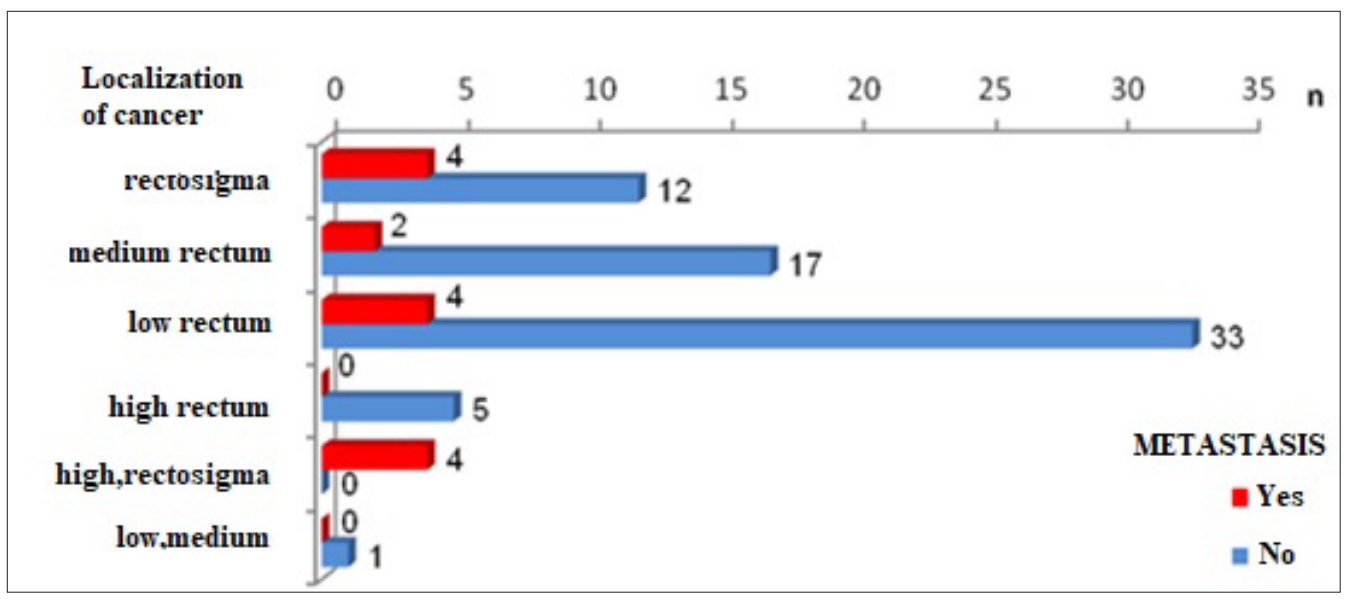

Figure 4: Graphic presentation of localization of the rectal cancer with and without MS deposits.

Table 4: Localization of the rectal cancer with and without MS deposits.

\begin{tabular}{|c|c|c|c|c|c|c|c|c|}
\hline \multirow[b]{2}{*}{ MS } & \multicolumn{7}{|c|}{ Localization of the Rectal Cancer } & \multirow[t]{2}{*}{ p=Level } \\
\hline & $\mathbf{n}$ & $\begin{array}{c}\text { Rectosigmoid } \\
\text { part } \\
\text { n }(\%)\end{array}$ & $\begin{array}{c}\text { Mid } \\
\text { rectum } \\
\text { n (\%) }\end{array}$ & $\begin{array}{c}\text { Low } \\
\text { rectum } \\
\text { n (\%) }\end{array}$ & $\begin{array}{l}\text { Proximal } \\
\text { rectal part } \\
\text { n (\%) }\end{array}$ & $\begin{array}{c}\text { Proximal and } \\
\text { rectosigmoid } \\
\text { part } \\
\text { n }(\%)\end{array}$ & $\begin{array}{l}\text { Low and } \\
\text { mid rectum } \\
\text { n (\%) }\end{array}$ & \\
\hline Yes & 14 & $4(25)$ & $2(10.53)$ & $4(10.81)$ & 0 & $4(100)$ & 0 & $\mathrm{p}=0.002 \mathrm{sig}$ \\
\hline No & 68 & $12(75)$ & $17(89.4)$ & 33(89.19) & $5(100)$ & 0 & $1(100)$ & \\
\hline
\end{tabular}

Fisher exact test, two tailed, $\mathrm{p}=0.002$.

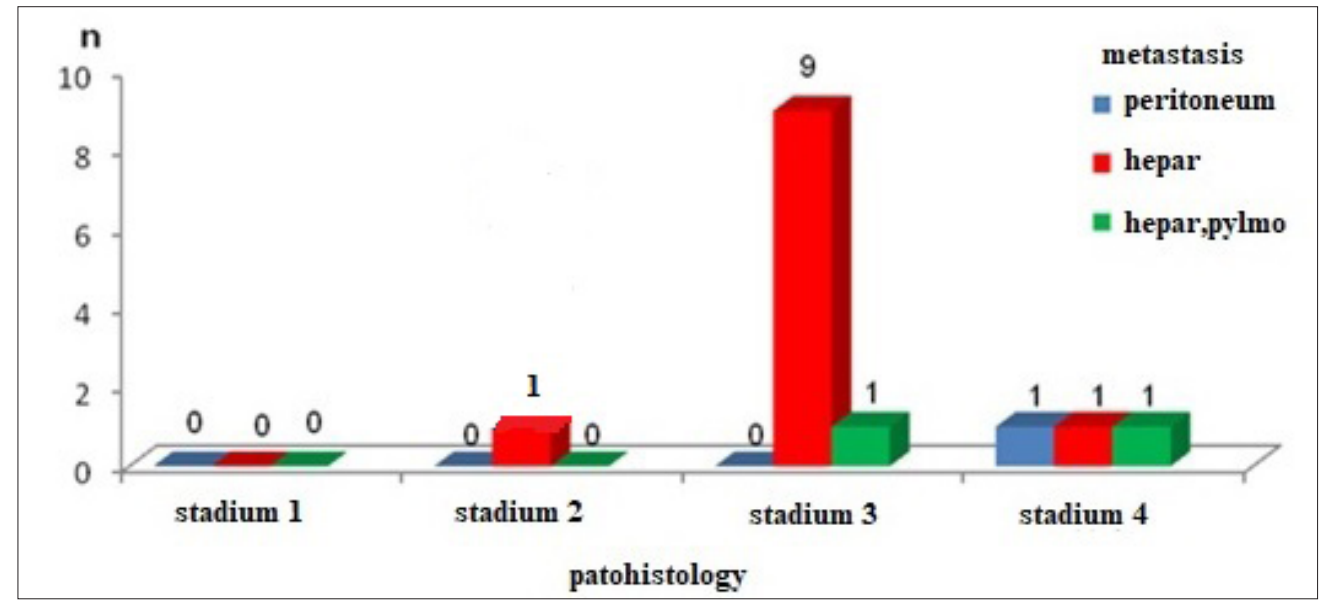

Figure 5: Graphic presentations of the presents of MS deposits according to the T stage of rectal cancer.

Table 5: Presents of MS deposits according to the T stage of rectal cancer.

\begin{tabular}{|c|c|c|c|c|c|c|}
\hline \multirow{2}{*}{$\begin{array}{c}\text { MS } \\
\text { Deposits }\end{array}$} & $\mathrm{n}$ & $\begin{array}{c}\text { Stage T1 } \\
\mathrm{n}(\%)\end{array}$ & $\begin{array}{c}\text { Stage T2 } \\
\mathrm{n}(\%)\end{array}$ & $\begin{array}{c}\text { Stage T3 } \\
\mathrm{n}(\%)\end{array}$ & $\begin{array}{c}\text { Stage T4 } \\
\mathrm{n}(\%)\end{array}$ & \begin{tabular}{c} 
p=level \\
\cline { 2 - 6 }
\end{tabular} \\
\hline Yes & 14 & 0 & $1(12.5)$ & $10(18.18)$ & $3(25)$ & $\mathrm{p}=0.65 \mathrm{~ns}$ \\
\hline No & 68 & $7(100)$ & $7(87.5)$ & $45(81.82)$ & $9(75)$ \\
\hline
\end{tabular}

Fisher exact test, two tailed, $\mathrm{p}=0.649$. 


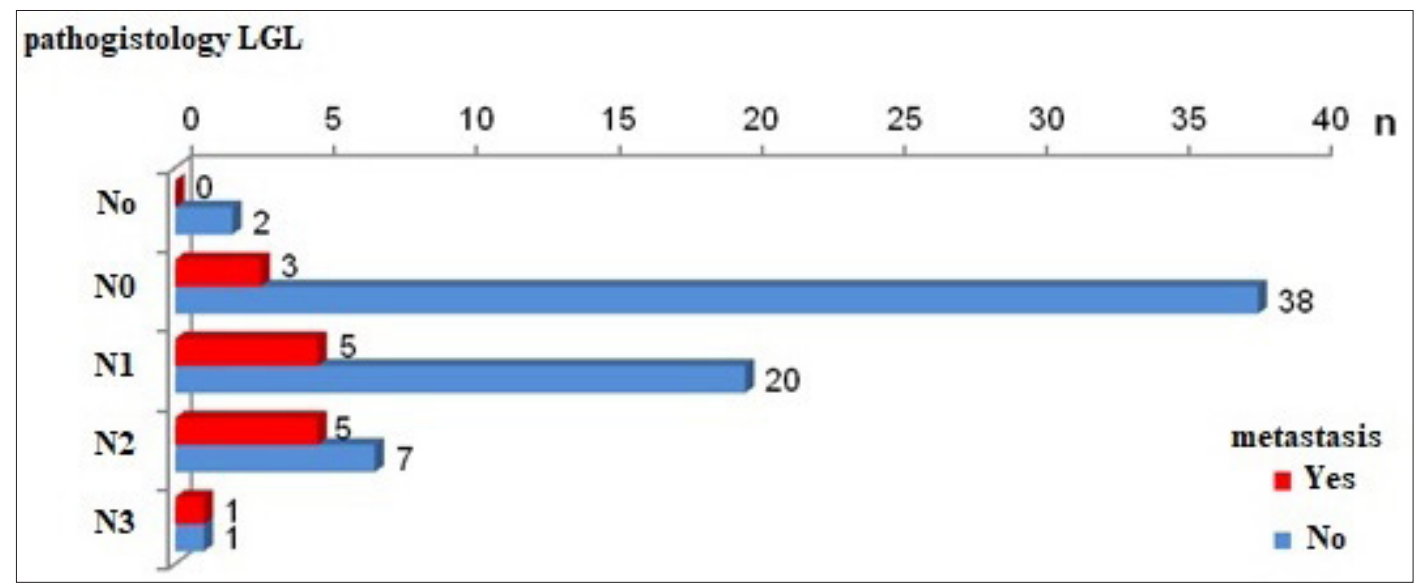

Figure 6: Graphic presentation of rectal cancer with and without MS deposits according to N stage.

Table 6: Rectal cancer with and without MS deposits according to N stages.

\begin{tabular}{|c|c|c|c|c|c|c|c|}
\hline \multirow[b]{2}{*}{$\begin{array}{c}\text { MS } \\
\text { Deposits }\end{array}$} & \multicolumn{6}{|c|}{ Patohistology Lymph Nodes } & \multirow[b]{2}{*}{ p=level } \\
\hline & $\mathbf{n}$ & $\begin{array}{c}\text { No + lymph } \\
\text { nodes } \\
\text { n (\%) }\end{array}$ & $\begin{array}{c}\text { N0 } \\
\text { n (\%) }\end{array}$ & $\begin{array}{c}\text { N1 } \\
\text { n (\%) }\end{array}$ & $\begin{array}{c}\text { N2 } \\
\text { n (\%) }\end{array}$ & $\begin{array}{c}\text { N3 } \\
\text { n (\%) }\end{array}$ & \\
\hline Yes & 14 & 0 & $3(7.32)$ & $5(20)$ & $5(41.67)$ & $1(50)$ & $\mathrm{p}=0.031 \mathrm{sig}$ \\
\hline No & 68 & $2(100)$ & $38(92.68)$ & $20(80)$ & $7(58.33)$ & $1(50)$ & \\
\hline
\end{tabular}

Fisher exact test, two tailed, $\mathrm{p}=0.031$.

\section{Discussion}

The presence of metastatic disseminated disease in the case of a diagnosis of rectal cancer is an advanced stage of the disease. That is why metastatic disseminated disease in the case of primary rectal cancer is a challenge in treatment that requires a special and comprehensive approach. Regardless of the progress of the preoperative neoadjuvant chemo-radiotherapy approach, dealing with distant metastases is still an important factor influencing rectal cancer to be an incurable disease. Circulating tumor cells are cells from the primary tumor that are found in the blood of patients without the presence of metastases. The presence of circulating tumor cells is a prognostic biomarker in patients with rectal cancer [16]. Different parts of the rectum have different blood supply. Three main arteries supply blood to the rectum. The upper rectal artery which is a branch of the a. mesenterica inferior supplies blood to the upper part of the rectum. The middle rectal artery which originating from the anterior branch of the a. iliaca interna or from the lower visceral arteries supplies the middle part of the rectum. The inferior rectal artery originates from the internal pudendal artery and supplies the low rectum [17]. Because the blood supply to the rectum is through different arteries, circulating cancer cells depend on the location of the tumor [18]. Differences in locally advanced disease, such as the depth of tumor invasion, the presence of lymph node metastases, and incomplete tumor resection, correlate directly with tumor cells in the central venous blood compartment rather than in the mesenteric venous blood compartment [19]. Hepatic venous metastases are much more common than those in the peripheral venous compartments [20].

For rectal carcinoma localized to the proximal end of the middle rectum as well as the upper rectum, it is important to determine the distance to the peritoneal reflection because the rectum from $6 \mathrm{~cm}$ to $8 \mathrm{~cm}$ of the anal verge to the proximal part is covered with peritoneum on its anterior and lateral surface [21]. Involvement of the peritoneum is very important in the further possible spread of intraperitoneal metastases [22]. In the lower parts of the rectum, mesorectal fat surrounds the rectum, and it is circumferentially surrounded by a mesorectal fascia. While in the higher parts the peritoneum covers the anterior part of the mesorectal fat to a point called the anterior peritoneal reflection. From the anterior peritoneal reflection, the peritoneum extends posteriorly and bypasses the rectosigmoid junction. Peritoneal reflection is presented as a thin $(0.5 \mathrm{~mm}-1 \mathrm{~mm})$ low signal line in the T2 waited images that bind the anterior aspect of the rectum. On sagittal projection, peritoneal reflection can be visualized above the seminal vesicles in a man and the utero-cervical angle in a woman. The relationship of the tumor with the peritoneal reflection should be carefully analyzed [23,24].

Mucinous rectal adenocarcinomas have a higher tendency to metastasis and are usually more advanced at the time of diagnosis. Of great importance is the fact whether the tumor penetrates the sacral fascia. With standard total mesorectal excision these lymph nodes cannot be removed [25]. Detection of malignant extramesorectal lymph nodes indicates the need for a more 
extensive surgical approach, as well as the use of radiotherapy in high-risk areas. Extramural vascular invasion (EMVI) is suspected when the veins near the tumor are irregular or dilated. EMVI was accepted as an independent prognostic indicator in rectal cancer associated with a higher incidence of metastases, local recurrences, a poorer response to preoperative chemo-radiotherapy, and, above all, a lower survival rate [26]. It has recently been shown that the rate of distant MS deposits and the response to preoperative chemo-radiotherapy are strongly correlated with the size of the blood vessels involved [27]. Metastatic deposits in this study were detected in $17.1 \%$ (14) patients, of whom 11 had liver metastases, 2 patients had liver and lung metastases, and one patient had peritoneum. In this group of patients with rectal cancer, a statistically significant difference was confirmed between male and female patients depending on the occurrence of metastases $(\mathrm{p}=0.02)$. There are significant differences between male and female responders with metastatic dissemination, more often metastasis is present in male respondents-25\% (12) versus $5.9 \%$ (2) female responders. The occurrence of metastases was significantly associated with pathohistological findings of extra mural vascular invasion $(\mathrm{p}=0.014)$. Metastases were detected in $78.6 \%$ (11) EMVI-positive patients and $21.4 \%$ (3) EMVI-negative patients. In the group of patients without metastases, $42.65 \%$ (29) patients were EMVI positive, 57.35\% (39) were EMVI negative. All this is a confirmation of the results of the world literature on the importance of extramural invasion in the overall pathology of rectal cancer. Patients with and without metastases had a similar average age, about 67 years, so there is not statistically significant difference $(66.85 \pm 9.1 v s .66 .62 \pm 10.01)$. The occurrence of metastases significantly depended on the localization of rectal cancer $(p=0.002)$. Metastases were detected in all 4 patients with localized rectosigmoid carcinoma of the colon and upper rectum, in $25 \%$ (4) patients with rectosigmoid carcinoma, $10.5 \%$ (2) patients with middle rectal cancer, and in $10.8 \%$ (4) patients in whom the localization of the cancer was at the level of the lower rectum. This is due to the embryological origin of the proximal and distal rectum and the blood drainage through the portal bloodstream of the rectosigmoid and proximal rectum.

\section{Conclusion}

Rectal cancer is spread malignant disease worldwide and it is third common malignancy after breast and lung cancer in woman and prostatic and lung cancer in male population. Occurrence of metastatic dissemination when primary rectal cancer has been diagnosed is not so rare condition but is very important to be aware of the factors that are associated with metastatic dissemination of rectal cancer. Knowing the possibility of dissemination can lead to increase the 5 years survival rate and decrease the percentage of incurability.

\section{References}

1. Langley RR, Fidler IJ (2011) The seed and soil hypothesis revisited-the role of tumor-stroma interactions in metastasis to different organs. Int J Cancer 128(11): 2527-2535.
2. Fidler I (2003) The pathogenesis of cancer metastasis: the 'seed and soil' hypothesis revisited. Nat Rev Cancer 3(6): 453-458.

3. Riihimaki M, Hemminki A, Fallah M, Thomsen H, Sundquist K, et al. (2014) Metastatic sites and survival in lung cancer. Lung Cancer 86(1): 78-84

4. Grimminger PP, Brabender J, Warnecke-Eberz U, Narumiya K, Wandhöfer C, et al. (2010) XRCC1 gene polymorphism for prediction of response and prognosis in the multimodality therapy of patients with locally advanced rectal cancer. Journal of Surgical Research 164(1): e61-e66.

5. Vineis P, Brennan P, Canzian F, John PAI, Giuseppe M, et al. (2008) Expectations and challenges stemming from genome-wide association studies. Mutagenesis 23(6): 439-444.

6. Jemal A, Bray F, Center MM, Ferlay J, Ward E, et al. (2011) Global cancer statistics. CA Cancer J Clin 61(2): 69-90.

7. Jemal A, Siegel R, Xu J, Ward E (2010) Cancer statistics. CA Cancer J Clin 60(5): 277-300.

8. Cedermark B, Dahlberg M, Glimelius B, Påhlman L, Rutqvist LE (1997) Improved survival with preoperative radiotherapy in resectable rectal cancer. N Engl J Med 336(14): 980-987.

9. Sauer R, Fietkau R, Wittekind C, Rödel C, Martus P, et al. (2003) Adjuvant vs. neoadjuvant radiochemotherapy for locally advanced rectal cancer: The german trial CAO/ARO/AIO-94. Colorectal Dis 5(5): 406-415.

10. Hodgman CG, MacCarty RL, Wolff BG, May GR, Berquist TH, et al. (1986) Preoperative staging of rectal carcinoma by computed tomography and $0.15 \mathrm{~T}$ magnetic resonance imaging. Preliminary report. Dis Colon Rectum 29(7): 446-450.

11. Schnall MD, Furth EE, Rosato EF, Kressel HY (1994) Rectal tumor stage: correlation of endorectal MR imaging and pathologic findings. Radiology 190(3): 709-714.

12. Freedman LS, Macaskill P, Smith AN (1984) Multivariate analysis of prognostic factors for operable rectal cancer. Lancet 2(8405): 733-736.

13. Smith NJ, Barbachano Y, Norman AR, Swift RI, Abulafi AM, et al. (2008) Prognostic significance of magnetic resonance imaging-detected extramural vascular invasion in rectal cancer. Br J Surg 95(2): 229-236.

14. Al-Sukhni E, Milot L, Fruitman M, Joseph Beyene, Charles Victor J, et al. (2012) Diagnostic accuracy of MRI for assessment of T category, lymph node metastases, and circumferential resection margin involvement in patients with rectal cancer: A systematic review and meta-analysis. Ann Surg Oncol 19(7): 2212-2223.

15. Beets-Tan RG, Beets GL, Vliegen RF, Kessels AG, Van Boven H, et al. (2001) Accuracy of magnetic resonance imaging in prediction of tumour-free resection margin in rectal cancer surgery. Lancet 357(9255): 497-504.

16. Mercury Study Group (2006) Diagnostic accuracy of preoperative magnetic resonance imaging in predicting curative resection of rectal cancer: prospective observational study. BMJ 333(7572): 779.

17. Tang R, Wang JY, Chen JS, Chang-Chien CR, Tang S, et al. (1995) Survival impact of lymph node metastasis in TNM stage III carcinoma of the colon and rectum. J Am Coll Surg 180(6): 705-712.

18. Shepherd NA, Baxter KJ, Love SB (1995) Influence of local peritoneal involvement on pelvic recurrence and prognosis in rectal cancer. J Clin Pathol 48(9): 849-855.

19. Vliegen RF, Beets G, Von Meyenfeldt MF, Alfons GH, Etienne E, et al. (2005) Rectal cancer: MR imaging in local staging-is gadolinium-based contrast material helpful? Radiology 234(1): 179-188.

20. Harrison JC, Dean PJ, El Zeky F, Vander ZR (1994) From dukes through jass: Pathological prognostic indicators in rectal cancer. Hum Pathol 25(5): 498-505. 
21. Wolmark N, Fisher B, Wieand HS (1986) The prognostic value of the modifications of the Dukes' C class of colorectal cancer. An analysis of the NSABP clinical trials. Ann Surg 203(2): 115-122.

22. Maier A, Fuchsjager M (2003) Preoperative staging of rectal cancer. Eur J Radiol 47(2): 89-97.

23. Sunderland D (1949) The significance of vein invasion by cancer of the rectum and sigmoid: a microscopic study of 210 cases. Cancer 2(3): 429437.

24. Horn A, Dahl 0, Morild I (1990) The role of venous and neural invasion on survival in rectal adenocarcinoma. Dis Colon Rectum 33(7): 598-601.
25. Matsuoka H, Nakamura A, Sugiyama M, Hachiya J, Atomi Y, et al. (2004) MRI diagnosis of mesorectal lymph node metastasis in patients with rectal carcinoma. What is the optimal criterion? Anticancer Res 24(6): 4097-4101.

26. Wanebo HJ, Koness RJ, Vezeridis MP, Cohen SI, Wrobleski DE (1994) Pelvic resection of recurrent rectal cancer. Ann Surg 220 (4): 586-597.

27. Mirnezami AH, Sagar PM, Kavanagh D, Witherspoon P, Lee P, et al. (2010) Clinical algorithms for the surgical management of locally recurrent rectal cancer. Dis Colon Rectum 53(9): 1248-1257. 